\title{
ПРОБЛЕМАТИКА УПРАВЛЕНИЯ ЛОГИСТИЧЕСКИМИ СЕРВИСНЫМИ ПОТОКАМИ ПРЕДПРИЯТИЙ ИНДУСТРИИ ТУРИЗМА И ГОСТЕПРИИМСТВА
}

\begin{abstract}
Крайнова Ольга Сергеевна, канд. экон. наук, дои., зав. кафедрой туризма филиала ЧОУ ВО «Московский университет им. С.Ю.Витте» в г. Нижнем Новгороде (2. Нижний Новгород)
\end{abstract}

В статье отражены проблемные аспекты реализации турпродукта и выявлена необходимость формирования лояльности клиентов-туристов, что может быть обеспечено за счет внедрения логистического подхода к управлению сервисными потоками в индустрии туризма и гостеприимства.

Ключевые слова: лояльность, клиент-турист, индустрия туризма и гостеприимства, логистический подход, качество услуги.

Актуальность рассматриваемых в рамках статьи направлений оптимизации сервисных потоков за счет внедрения логистического подхода к управлению ими проявляется в том, что для современных условий хозяйствования неотъемлемой частью эффективной работы предприятий в сфере услуг становится формирование и совершенствование их сервисной политики с учетом того, что на рынке туристских услуг сервис выступает, с одной стороны, как продукт, с другой стороны, как набор дополнительных услуг, поддерживающих обслуживание туристов на маршрутах.

Одним из основных недостатков современных систем обслуживания клиентов туристских компаний заключается в том, что клиент фактически обезличивается, рассматривается как «лицевой счёт». Такой подход к клиенту может привести к образованию упущенной выгоды, которая связана с недоучётом потребностей и возможностей туристов. Во многих ситуациях размер этой упущенной выгоды весьма значителен, поэтому в условиях 
обостряющейся конкурентной борьбы за туриста на первый план выходит индивидуальный подход к обслуживанию, способный найти наиболее рациональный индивидуальный баланс интересов субъектов туристского рынка.

Одной из основных проблем при этом становится проблема предсказания оттока клиентов (churn prediction) или оценка их «лояльности» при реализации турпродуктов, а также после туристских путешествий, что связано с предоставлением туристских услуг ненадлежащего качества. Как показывают оценки экспертов, привлечение нового клиента стоит примерно в 10 раз больше, чем удержание старого, а возврат ушедшего - в 100 раз больше, отсюда следует логичный вывод о необходимости управления взаимоотношениями с клиентами (до момента обслуживания на маршруте) и, конечно, уже туристов, испытывающих на себе результаты предоставления услуг размещения, перевозки и пр. (в зависимости от типа турпродукта и его наполнения).

Глобализация рынков и всепроникающие инфокоммуникации открыли для многих туристов истинную свободу выбора наполнения турпродуктов, альтернативу ценовой политики и выбора конкретных поставщиков услуг, а новейшие технологии и организационные процессы позволили предложить услуги, сформированные по индивидуальным заказам. Транснациональные сети и интернет-провайдеры сделали бронирование услуг простыми и удобными, а расширение рынков и отсутствие территориальных границ предоставили туристам безграничный набор альтернатив, при этом их выбор во-многом определяется не только качеством турпродукта, но и уровнем дополняющего его сервиса.

Эффективное управление отношениями с клиентами компании в рамках общего логистического управления сервисными потоками стало важнейшим фактором развития, а построение клиентоориентированной структуры оказалось одной из самых актуальных целей организации. Основополагающим мотивом формирования программ лояльности является 
предоставление клиентам выгод: материальных, эмоциональных, психологических [3]. Следовательно, в процессе формирования комплекса лояльности важно предусмотреть наличие в нем различных мер, направленных на обеспечение клиентов компании различными преференциями.

Однако необходимо отметить, что удовлетворенность туристов не всегда влечет неоднократность покупки турпродуктов и вообще увеличение продаж в принципе, не менее половины туристов "удовлетворенных" меняют поставщиков услуг. Такой разрыв между лояльностью и удовлетворенностью означает возможное наличие иных компонентов, которые влияют на становление лояльности и охарактеризованы как элементы модели «gар» в теории Гронроуза.

Компоненты "поведенческой" лояльности (значения которых можно получить из базы данных по потребителям) определяются следующим образом:

- перекрестная продажа - это увеличение количества дополнительных услуг туроператора, которые были приобретены в конкретный период во времени; - увеличение покупок - это общая сумма или доля от данной суммы увеличения размера покупки одного и того же турпродукта в определенный период времени (глубина посещений туристом туристско-рекреационной территории);

- повторные покупки - количество повторных покупок.

Сложность оценки качества предоставления туристских услуг с позиции туроператора, формирующего турпродукт и туриста, во многом вызвано расхождением (рассогласованием) в ожидаемом и фактическом качестве. В западной экономической литературе это расхождение часто называют термином «разрыв» (gap) GAP модель использует предложенный Гронрузом разрыв «ожидания потребителя - восприятие полученной услуги» [5]. Для описания воспринятого качества предполагается существование двух параметров качества - технического качества (качества выхода) и 
функционального качества (качества процесса взаимодействия). При этом техническое и функциональное качество, а также имидж компании определяют ожидание потребителей (рис. 1).

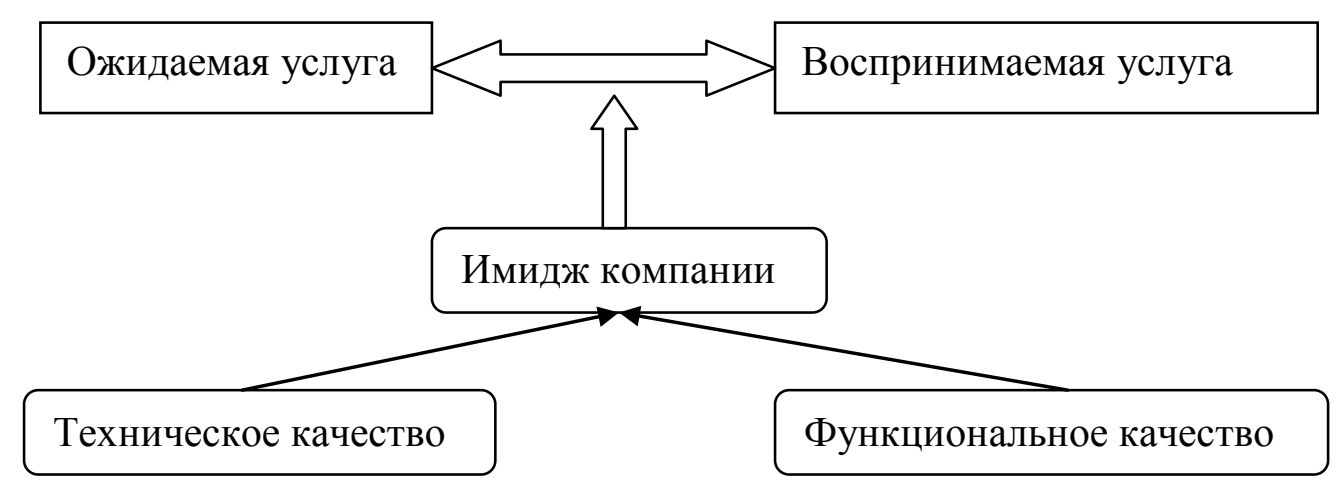

Рисунок 1 - Модель качества К.Гронруза [5]

Идеи воспринятого качества К. Гронруза развиты в GAP модели А. Парашураман, В. Зайтамл, Л. Берри (рис. 2).

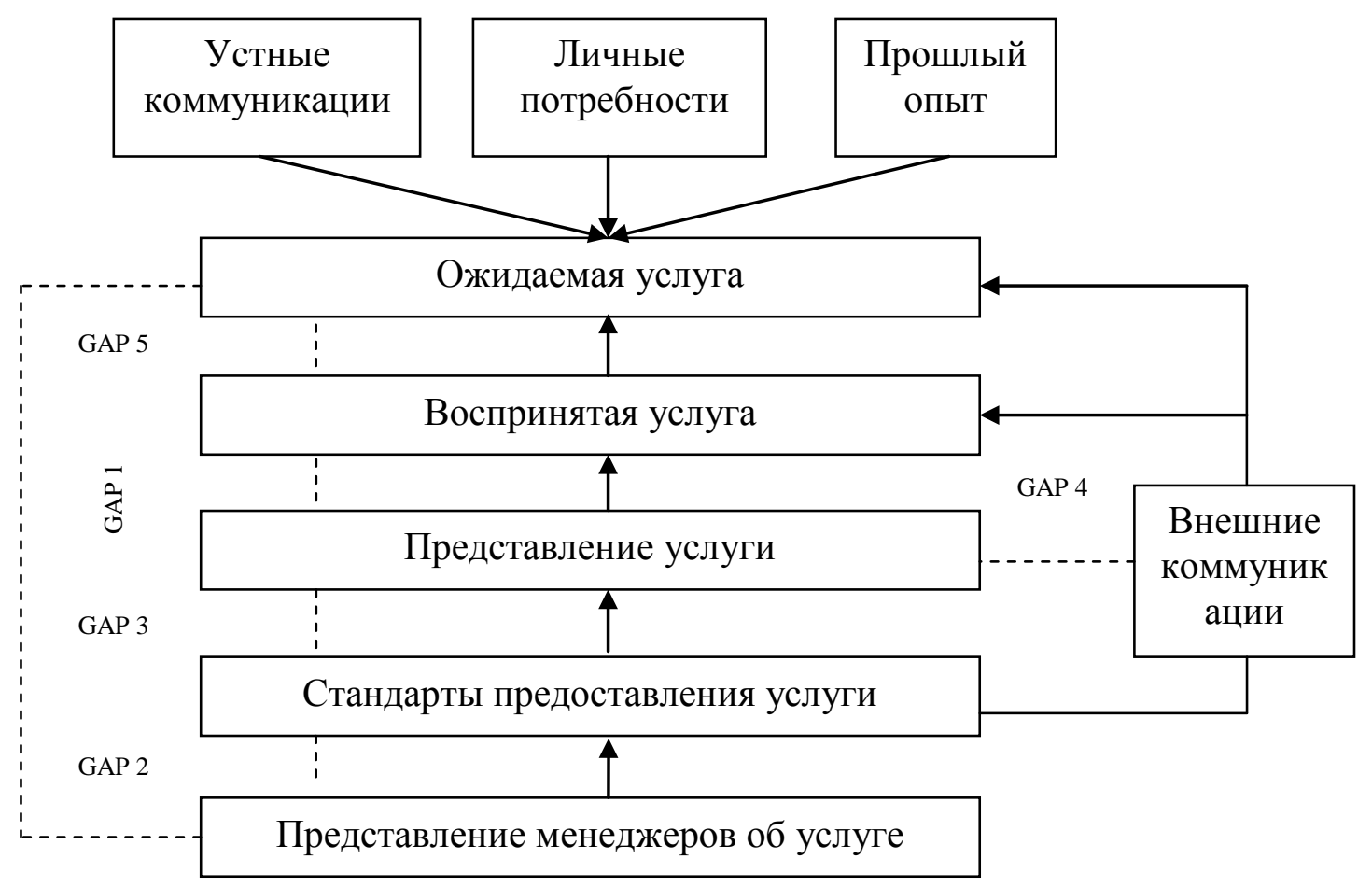

Рисунок 2 - Модель GAP (А. Парашураман, В. Зайтамл, Л. Берри) [6]

GAP модель использует предложенный Гронрузом разрыв «ожидания потребителя - восприятие полученной услуги». В основании модели лежит 
набор разрывов. В соответствии с моделью, качество услуги с точки зрения потребителя зависит от величины и направления разрыва между ожиданиями потребителя об услуге и восприятием услуги после ее получения (Разрыв 5). Разрыв 5 определяется другими существующими в модели разрывами (1-4): Разрыв 5 =f(Разрыв 1; Разрыв 2; Разрыв 3; Разрыв 4). Чем больше разрыв 5, тем ниже качество предоставляемой услуги.

В основании модели лежит набор разрывов, таких как:

- разрыв 1: ожидания потребителей - представления менеджеров об этих ожиданиях;

- разрыв 2: представления менеджеров - стандарты предоставления услуги;

- разрыв 3: создание стандартов предоставления услуги - предоставление услуги;

- разрыв 4: внешние коммуникации - предоставление услуги.

Таким образом, качество услуг определяется совокупным ожиданием покупателя в смысле минимальных расхождений между ожидаемыми и фактическими параметрами, хотя, конечно, оценка расхождений будет субъективной.

Именно в момент соотнесения воспринятого качества с ожидаемым важно, на наш взгляд, заложить фундамент дальнейшей лояльности клиентатуриста. Это обеспечивается, прежде всего, достижением удовлетворенности потребностей туриста на конкретном маршруте на данный момент с максимальным качеством и удобством взаимодействия $\mathrm{c}$ компаниейтуроператором.

Типичные проблемы управления сервисными потоками и потоками клиентов при реализации турпродукта туроператорами и турагентами:

- недостаточно эффективное управление клиентской базой;

- отсутствие четкой политики, направленной на удержание клиентов и повышение их лояльности к компании в целом и ее услугам; 
- отсутствие интеграции сервисной политики со средствами телекоммуникаций (CallCenter и запись телефонных переговоров);

- нечеткое сегментирование туристов-клиентов (по лояльности, периодичности приобретения турпродукта, прочим характеристикам потребительского поведения и социально-демографическим критериям);

- отсутствие нематериального стимулирования «нужного» поведения клиента.

Конкретизация типовых проблем и их характеристика:

1) нечеткое, фрагментарное управление клиентской базой проявляется в отсутствии сбора всех данных о клиентах в единую клиентскую базу компании, отсутствии подробной характеристики о каждом клиенте и контактном лице, расширенной аналитики по клиенту, динамики изменения состояния отношений с клиентами, возможности быстрого ввода и доступа к информации о клиенте;

2) нерациональное управление контактами с клиентами - не ведется учет истории контактов с клиентами и регистрация потребности клиентов, отсутствует диспетчеризация контактов клиентов в режиме реального времени, оперативная передача информации между отделами, планирование контактов, шаблоны типовых контактов с клиентами;

3) невозможность управления рабочим временем (тайм-менеджмент) и отсутствие координации между подразделениями, участвующими в процессе оказания услуг - отсутствие планирования и контроля действий, координации работы во времени, системы напоминаний и выдачи заданий. Также отсутствие диспетчеризации рабочего места руководителей подразделений, менеджеров по приему и распределению входящих событий, контроль загруженности сотрудников подразделений с возможностью распределения/перераспределения загрузки между ними;

4) фрагментарное управление продажами - не ведется учет управления стадиями и этапами продажи на основе бизнес-процессов, создание типовых 
шаблонов действий по продаже, механизм автоматической подготовки коммерческих предложений и договоров;

5) частично составляются аналитические отчеты - отсутствует многофакторный анализ контактов (сегментов) и продаж, анализ состояния работы с клиентами.

Ввиду наличия проблем в управлении сервисными потоками предприятий индустрии туризма и гостеприимства, возникает востребованность применения технологий логистического управления потоками.

Особенности такого восприятия состоят в понимании концепции логистики для туризма, согласно которому не рассматриваются человеческие потоки, а выделяется управление «потоком услуг - как субъектом» и «потоком клиентов - как объектом». Причем, и поток услуг в данном контексте и поток клиентов в самом процессе оказания услуги находятся на различных уровнях взаимодействия, что отражается видом услуг в их классификации по степени контакта в процессе обслуживания на маршруте, будь-то «чистые», смешанные и квазипроизводственные услуги.

В соответствии с особенностями реализации турпродукта и спецификой обслуживания туристов на маршрутах с учетом переноса акцентов на самодеятельный туризм и сокращения объемов международного выездного туризма ввиду геополитических и валютных колебаний рынка, можно констатировать необходимость поиска инструментов управления взаимоотношениями с клиентами и оптимизации качества сервиса, что направлено на повышение конкурентоспособности предприятий индустрии туризма и гостеприимства.

Список источников и литературы:

1. Бабушкина А.Ю. Программы лояльности: теория и практика // Российское предпринимательство. - 2011. — № 7 Вып. 2 (163)._ С. 94-98. 
2. Мешков А.А. Индивидуальные ценности как основа продвижения продуктов на рынке // Труды вольного экономического общества России. Сборник научных статей. - М.: Вольное экономическое общество России. - ГОУ ВПО «МАТИ» - Российский государственный технологический университет им. К.Э. Циолковского, 2010. Том 130. - С. 134-141.

3. Химич Ю.С. Повышение конкурентоспособности предприятия с помощью программ лояльности // Российское предпринимательство. - 2011. — № 8 Вып. 2 (190).— С. 55-60.

4. Чурочкин В. Оценка лояльности клиентов: основные критерии [Электронный ресурс]: - Электрон. ст. - Режим доступа к ст. URL: http://www.cloyalty.info/loyalty_articles.html?id=28

5. Gronroos, C., Strategic Management and Marketing in the Service Sector, Helsingfors Swedish School of Economics and Business Administration, 1982.

6. Parasuraman, A., Zeuthaml, V.A., Berry, L.L. A Conceptual Model of Service Quality and its Implications for Future Research. Journal of Marketing, Vol. 49, Fall 1985. 